The automatic separator in organic preparations: I. N. Hulmman, ANNE W. Davis and H. T. CuARKE. Principle of automatic separator. Separation of butyl alcohol or amyl alcohol and water. Steam distillation of aniline and similar liquids. Preparation of anhydrous oxalic acid, butyl ether, butyl oxalate, trimethylene chlorohydrin, and glycerol dichlorohydrin.

Some condensed rings containing arsenic: $\mathrm{W}$. Lee Lewis and W. V. Evans. Oxydiphenylene chlor arsine is prepared by a modification of Pope's method condensing diphenyl ether and arsenic chloride in the presence of aluminium chloride. With the Grignard reagent mixed arsines of the type oxydiphenylene ethyl arsine are obtained. The brom, iodo, cyan, sulphocyan and hydrosulphide derivatives were prepared. Chlorination gave oxydiphenylene trichlorarsine which on careful hydrolysis gave the oxychloride. Bromination with subsequent hydrolysis yielded oxydiphenylene arsenic acid and its metal and alkaloidal salts. The condensation of diphenylmethane and diphenyl sulfide with arsenic chloride is being studied.

$A$ cooperative pamphlet on organic chemical preparations: Roger AdaMs, O. K. KaMm, H. T. Clarke, J. B. Conant. An annual pamphlet is to be published containing the detailed directions for the preparation of various reagents which may have been produced in the laboratories in which the above authors work. The directions are to be tested out in one of the other laboratories and not until the results can be duplicated are they to be published. A discussion of the reaction and bibliography of other methods of preparation are included. It is hoped that othens who may be carrying on investigations in organic research will be willing to contribute methods of preparation for various reagents which they may have developed in detail in their laboratories. These will be tested out and published with the others.

The reaction between aldehydes and acid halides: Roger Adams, H. E. French and L. H. Ulich. It. has been shown that the reaction between aromatic acid halides and aliphatic or aromatic aldehydes and between aliphatic acid halides and aliphatic aldehydes to give compounds of the general formula RCOOCHXR is very general. Early work in this field showed that a number of aliphatic halides and aldehydes reacted together to give compounds of this type but until the above research was undertaken no substances were obtained between aromatic acid halides and aliphatic aldehydes with the exception of the compounds from benzoyl chloride and formaldehyde and no compounds from aromatic acid halides and aromatic aldehydes were produced with the exception of the compound from benzoyl bromide and benzaldehyde. The reaction between aliphatic acid halides and aromatic aldehydes does not seem to run so smoothly and results are not yet available on this point. These halogenated esters that are produced react in many cases merely like a mixture of the acid halides and aldehydes. In other cases, the halogens react like the halogens in alkyl halides.

The preparation and physiological action of oxazolidones and their decomposition into substituted B-amino ethyl alcohols: RoGER ADAMs and J. B. Segur. The oxazolidones are readily produced by condensing phosgene with ethylene chlorohydrin to give beta-chloroethyl chlorocarbonate. This is condensed with aniline to give the corresponding urethane derivative and then by treatment of this latter substance with alkali, the oxazolidone is produced as follows:

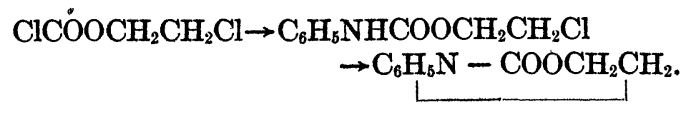

If the oxazolidone is treated with excess of concentrated alkali or if the urethane derivative is treated directly with excess of concentrated alkali, very good yields of $\mathrm{N}$-aryl amino alcohols are produced.

$$
\mathrm{C}_{6} \mathrm{H}_{5} \mathrm{~N}-\mathrm{COOCH}_{2} \mathrm{CH}_{2} \rightarrow \mathrm{C}_{6} \mathrm{H}_{5}-\mathrm{NHCH}_{2} \mathrm{CH}_{2} \mathrm{OH} \text {. }
$$

The paraethoxy phenyl oxazolidone has about the same toxicity as phenacetin and as an antipyretic possesses slightly greater value than phenacetin. Charles L. Parsons, Secretary

( $T o$ be continued)

\section{THE NORTH CAROLINA ACADEMY OF SCIENCE}

THe nineteenth annual meeting of the North Carolina Academy of Science was held April 30 and May 1, 1920, at the North Carolina State College of Agriculture and Engineering, West Raleigh, N. C. At the same time the spring meeting of the North Carolina Section of the American Chemical Society was held.

Among the more important business matters discussed and acted upon were those relating to the affiliation of the academy with the American Asso- 
ciation for the Advancement of Science, the decision of which rests with the executive committee with power to act; and the matter of seeking state support from the next legislature which was left in the hands of the executive committee for action and if found favorable the president was authorized to appoint a committee to approach the legislature in an effort to obtain $\$ 1,000$ per year to be expended for publications and the furthering of research work.

A total of twenty-eight new names was added to the membership list. The membership now includes 113 individuals interested in science in North Carolina.

The following officers were elected for the year 1921:

President: Z. P. Metcalf, professor of zoology and entomology, State College, West Raleigh, N. C.

Vice-president: J. M. Bell, professor of physical chemistry, University of North Carolina, Chapel Hill, N. C.

Secretary-Treasurer: R. W. Leiby, assistant entomologist, research, State Department of Agriculture and Agricultural Experiment Station, Raleigh, N. C.

Additional members executive committee: H. R. Totten, University of North Carolina; R. N. Wilson, Trinity College; F. A. Wolf, State College, Agricultural Experiment Station.

The meeting was featured by the address of the retiring president, Dr. A. H. Patterson, who spoke on "The Einstein theory of relativity." Other papers presented were:

Functions of circular curves simplified: T. F. HICKERSON.

Some biological aspects of the tidal zone region of the North Carolina coast: Z. P. METCALF.

Recent growth and depletion of sea beaches on the North Carolina coast. (Lantern): CoLLIER CoBr.

Some remarkable forms of the skeletal element in Lithistid sponges: H. V. WLLSON.

Animal locomotion: H. H. BRIMLEY.

Single spore cultures of Coprinus radiatus: H. $\mathrm{R}$. TOTTEN.

Genera of lower Basidoimycetes new to the United States: W. C. Coker.

Turtles of North Carolina: C. S. BRIMLEY.

Electro-endosmosis of clays: THORNDXKE SAville.

The life-history of a gall-making Psyllid Pachypsylla mamma Riley. (Lantern): B. W. Welcs. Dreams and their causes, with examples: C. S. BRIMLEX.
A little-known vetch disease: F. A. WoLr.

Notes on the mosquito fauna of North Carolina: F. SHERMAN.

Agricultural geology: JoHN E. SмIтH.

The larger cornstalk borer Diatraea zeacolella Dyar. (Lantern): R. W. LEIBY.

The wing venation of the Heteroptera: HERBERT SPENCER.

An interesting fertilizer problem:.H. B. ARBUCKLE. $A$ list of Cicadellide taken at Swannanoa, North Carolina: Z. P. Metcalf and Herbert Osborn. $A$ phenomenal shoot (exhibit): B. W. Weuls.

A peculiar Mycorhiza-forming Rhizopogon on the roots of the pine: H. R. TOTrEN.

Effect of fertilizers on germination and seedling growth of corn and cotton. (Lantern): M. W. SHERWIN.

Behind the barrier beaches from Boston to Beaufort. (Lantern) : CoLLIER СoBB.

Some investigations on the compounds isolated from the Polypores: Joseph T. Matrox and RAYMOND BINFORD.

Effect of borax on plant growth: OscAR J. THEIS, JR., and H. B. ARBUCKLE.

Dyestuff situation in the United States: R. F. Revson.

New ethers: A. S. WHEELER and S. C. SMITH.

Further studies on the melting points of the nitrotoluenes: JAs. M. BELL.

Vitamines-a review: W. A. Withers.

Cymene, a new solvent: A. S. WHEELER.

$A$ color reaction for pure Cymene: A. S. WHEELER.

The conductivity of nonaqueous solutions: PAUL Gross.

Some new types of distillation apparatus: PAUL Gross.

R. W. LEIBY, Secretary-Treasurer

Raleigh, N. C.

\section{SCIENCE}

A Weekly Journal devoted to the Advancement of Science, publishing the official notices and proceedings of the American Association for the Advancement of Science Published every Friday by

\section{THE SCIENCE PRESS} LANCASTER, PA. GARRISON, N. Y. NEW YORK, N. Y.

Entered in the post-office at Lancaster, $\mathrm{Pa}$., as recond clase matter 